\title{
Abundance, zoonotic potential and risk factors of intestinal parasitism amongst dog and cat populations: The scenario of Crete, Greece
}

Despoina Kostopoulou ${ }^{1,2^{*}}$, Edwin Claerebout ${ }^{1}$, Dimitrios Arvanitis ${ }^{2}$, Panagiota Ligda ${ }^{1,2}$, Nikolaos Voutzourakis ${ }^{2}$, Stijn Casaert ${ }^{1}$ and Smaragda Sotiraki ${ }^{2}$

\begin{abstract}
Background: The objectives of this study were to evaluate the prevalence and infection intensity of intestinal parasites in different dog and cat populations in Crete, Greece, estimate the zoonotic risk and identify risk factors.

Methods: Faecal samples from shelter, household and shepherd dogs and shelter and household cats were analyzed using sedimentation/flotation techniques. Giardia and Cryptosporidium were detected by a quantitative direct immunofluorescence assay (IFA). PCR and sequencing was performed to evaluate the zoonotic potential of Giardia and Cryptosporidium positive samples.

Results: Totals of 879 dog and 264 cat faecal samples were examined. In dogs, the overall prevalence was $25.2 \%$ (Cl: 22.4-28.1) for Giardia spp.; 9.2\% (Cl: 7.3-11.1) for Ancylostoma/Uncinaria spp.; 7.6\% (Cl: 5.9-9.4) for Toxocara spp.; 5.9\% (Cl: 4.4-7.5) for Cryptosporidium spp.; 4.6\% (Cl: 3.2-5.9) for Cystoisospora spp.; 2.7\% (Cl: 1.7-3.8) for Toxascaris leonina; 1.7\% (Cl: 0.9-2.6) for Capillaria spp.; 0.8\% (Cl: 0.2-1.4) for taeniid eggs; 0.2\% (Cl: 0-0.5) for Dipylidium caninum; and $0.1 \%$ (Cl: 0-0.3) for Strongyloides stercoralis. In cats, the prevalence was 20.5\% (Cl: 15.6-25.3) for Giardia spp.; $9.5 \%$ (Cl: 5.9-13.0) for Cystoisospora spp.; 8.3\% (Cl: 5.0-11.7) for Toxocara spp.; 7.6\% (Cl: 4.4-10.8) for Ancylostoma/Uncinaria spp.; 6.8\% (Cl: 3.8-9.9) for Cryptosporidium spp.; 4.2\% (Cl: 1.8-6.6) for Capillaria spp.; 0.8\% (Cl: 0-1.8) for taeniid eggs; and 0.4\% (Cl: 0-1.1) for Hammondia/Toxoplasma. Concerning the risk factors evaluated, there was a negative association between age and Giardia infection and between age and T. leonina infection intensity for dogs. Sequencing results revealed the presence of mainly animal-specific $G$. duodenalis assemblages $C$ and $D$ in dogs and assemblages $F$, $\mathrm{C}$ and BIV-like in cats, with only a limited number of (co-)infections with assemblage A. As for Cryptosporidium, the dog-specific C. canis and the pig-specific C. scrofarum were detected in dogs and the cat-specific C. felis was detected in cats.

Conclusions: High levels of parasitism in both dogs and cats were recorded. Giardia was the most prevalent parasite in all dog and cat populations except for shepherd dogs. Genotyping results suggest a limited zoonotic risk of Giardia and Cryptosporidium infections from dogs and cats in Crete. Taeniid eggs were more prevalent in shepherd dogs suggesting access to carcasses and posing a threat for cystic echinococcosis transmission. Infection rates of Toxocara spp. in both dogs and cats show that companion animals could be a significant source of infection to humans.
\end{abstract}

Keywords: Intestinal parasites, Companion animals, Zoonotic, Molecular analyses

\footnotetext{
* Correspondence: nelly_kost@hotmail.gr

${ }^{1}$ Laboratory of Parasitology, Faculty of Veterinary Medicine, Ghent University,

Salisburylaan 133, Merelbeke B-9820, Belgium

${ }^{2}$ Veterinary Research Institute - Hellenic Agricultural Organization Demeter,

Thermi, Thessaloniki 57001, Greece
} 


\section{Background}

Intestinal parasite infections are still abundant in companion animals, despite all the highly efficient drug formulations available and the control measures taken by owners and veterinarians [1-8]. Moreover, parasites are responsible for some of the most important and well-recognized zoonoses transmitted from companion animals to man globally such as Giardia spp., Cryptosporidium spp., Toxocara spp., hookworms and Echinococcus granulosus [9-13].

Nowadays, changes due to climate alterations and social behaviour that affect humans' lives and consequently the lives of the animals which live close to them [14, 15], alter the interactions between humans and pathogens leading to (re)emergence of several diseases, including zoonotic ones $[16,17]$.

The distribution of zoonoses associated with companion animals is highly affected by animals' movements (between regions, countries and continents) which in fact are the means to relocate pathogens and vectors they harbour. The above is becoming more and more important since human travel continues to increase in parallel with the population and financial status increase, and when humans travel, they often take their companion animals, particularly dogs.

All the above is in fact unfolding the reasons why it is crucial to fill the gaps on the current distribution of these diseases in a constantly changing environment and to describe the risks associated with pet infection in order to assure their well-being and to prevent the free movement of zoonotic pathogens.

The aim of our study was to investigate the presence and infection intensity of intestinal parasites in dogs and cats, the risk factors (such as lifestyle, veterinary care, etc.) that influence those infections and their zoonotic potential. This was done by performing a cross-sectional epidemiological study within a defined animal/human community, i.e. the island of Crete, as a case scenario.

\section{Methods}

\section{Populations studied}

Faecal samples were collected from different dog populations (shelter, household and shepherd) as well as shelter and household cats in Crete Island in Southern Greece (Fig. 1), from October 2011 to January 2015.

Crete is the largest and most densely populated island of Greece (623,000 residents recorded in 2011) with a population well distributed in urban and rural areas. The island is also a highly popular tourist destination (approximately 3.5 million international tourist passengers' arrivals in 2013) (Region of Crete: www.crete.gov.gr). Moreover in Crete, in addition to the high number of companion animals, there is a significant livestock and wildlife population (Hellenic Ministry of Rural Development and Food: http://minagric.gr).

Since data on the precise population of pets in the location were not available, the sample size was determined estimating the dog and cat population size as "infinite". The prevalence of intestinal parasitism in different dog and cat studies in Europe varies enormously depending on the sampled animal population and the diagnostic techniques that were used [3, 6, 18-24]. In this study, in order to calculate the sample size (with a precision of $5 \%$ and a $95 \%$ confidence interval) we selected to relate our "expected prevalence" values to recent reports of Giardia prevalence in Europe. Therefore, the targeted sample size was defined as follows: for household dogs up to 200 dogs (reported prevalence 10-20\%); for shelter dogs up to 400 dogs (reported prevalence 20-50\%); for household cats 138 cats (reported prevalence $<10 \%$ ) and for shelter cats 385 cats (reported prevalence 10-50\%) [3, 5, 18, 19, 25-28]. For shepherd dogs there is little information available and given the difficulties in approaching and handling such dogs we aimed at collecting the maximum feasible number of samples. In order to achieve the most accurate coverage of the whole island, the animals enrolled in our

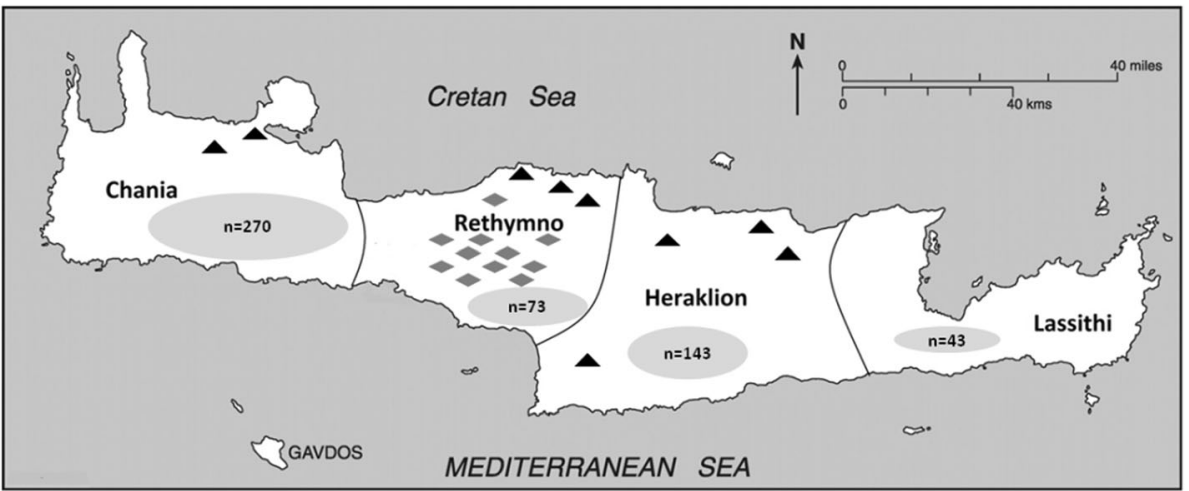

Fig. 1 Map of Crete demonstrating the locations of different sample points per animal population category. Key: triangles: shelter dogs/cats; rhombi: shepherd dogs; gray ellipses: household dogs/cats with the number of animals sampled 
study were allocated proportionally to the four different counties of the island according to the inhabitant's population density (Fig. 1).

Individual rectal faecal samples were randomly collected from dogs and cats of all ages with or without intestinal symptoms from 561 households, 11 shelters and 29 sheep and goat farms. After collection, the samples were immediately transported under vacuum [29] to the laboratory where they were stored at $4{ }^{\circ} \mathrm{C}$ and examined within 2 days. When a sample was found to be positive by coproscopic analysis for Giardia spp. or Cryptosporidium spp., it was stored at $-20{ }^{\circ} \mathrm{C}$ until DNA extraction was performed and molecular genotyping followed.

For every animal/sample, a data-form was completed by interviewing the owner or in case of shelters the person who was responsible for the animals, providing information on age, sex, breed, living conditions (indoors or outdoors), presence of other animals, the presence or absence of diarrhoea (up to maximum 1 month before sampling), if the animal had travelled recently and the antiparasitic treatment plan followed (including time of last treatment). Faecal consistency was recorded for all faecal samples. The consistency of individual faecal samples was scored using the following scale: 1 , formed; 2 , soft; 3 , diarrhoea, 4, haemorrhagic diarrhoea.

\section{Parasitological techniques}

The presence of worm eggs and protozoan oocysts was determined by applying two different methods, i.e. a sedimentation (acid/ether) and a sedimentation/flotation technique (using a saturated sugar salt solution as a flotation fluid with 1.28 specific gravity) [30]. For the detection of Giardia spp. and Cryptosporidium spp. (oo)cysts a quantitative direct immunofluorescence assay (IFA) based on the commercial MERIFLUOR Cryptosporidium/Giardia kit (Meridian Diagnostics Inc., Cincinnati, Ohio) was used [31, 32].

\section{Molecular analyses}

DNA was extracted from the positive Giardia spp. and Cryptosporidium spp. faecal samples using the QIAamp ${ }^{\circ}$ Stool Mini Kit (Qiagen, Hilden, Germany) according to the manufacturer's instructions. For the amplification of the Cryptosporidium $18 \mathrm{~S}$ ribosomal RNA gene (rDNA18S) and HSP70 gene, previously described PCR protocols were used $[33,34]$. For the identification of Giardia DNA, the Giardia rRNA 18S gene (rDNA 18S) [35], the $\beta$-giardin gene [36], the triose phosphate isomerase (TPI) gene [37] and the glutamate dehydrogenase $(\mathrm{GDH})$ gene [38] were used. Amplification products were visualised on $1.5 \%$ agarose gels with ethidium bromide. A positive (genomic DNA from a positive faecal sample) and negative (PCR water) control sample were included in each $\mathrm{PCR}$ reaction.
PCR products were purified and sequenced from both strands. PCR products were purified using the Qiaquick PCR purification kit (Qiagen) and fully sequenced using the Big Dye Terminator V3.1 Cycle sequencing Kit (Applied Biosystems, California, USA). Sequencing was performed by an external company (GATC Biotech) using the Big dye Terminator V3.1 Cycle sequencing Kit (Applies Biosystems) and the reactions were analyzed using a 3730xl DNA Analyzer (ThermoFisher Scientific). Sequences were assembled using Seqman 5.0 Software (Lasergene DNASTAR) and were aligned using the Basic Local Alignment Search Tool (BLAST) as well as compared with reference sequences using MegAlign (Lasergene DNASTAR) (Additional file 1). For multilocus genotyping Clustal X, 2.0.11 software was used and reference sequences were selected according to Caccio et al. [39].

\section{Statistical analysis}

Descriptive statistical analyses and multivariate methodologies were performed using the statistical language $\mathrm{R}$ [40] and the pscl package [41]. Two approaches were applied as follows.

\section{Multivariate binary logistic models}

The effect of the independent variables (age in months, gender, food, travel, neutering, living conditions, living with other animals, antiparasitic treatment, time between treatment and sampling date, diarrhoea during the last month, faecal score and type) on a sample being or not infected by a parasite was studied through the utilization of multivariate logistic models with forward LR selection. Initially, a test of the full model against a constant only model was performed in order to assess whether there was a statistically significant effect of the examined independent predictors on the response variable through the utilization of the Omnibus Tests of Model Coefficients, which uses the Chi-square test to see if there is a significant difference between the loglikelihood (-2LL) of the baseline model (constant model) and the model with the predictors. In addition, the Hosmer \& Lemeshow (H-L) test was performed to test whether the model provides a good fit to the data (Additional file 2: Table S1).

\section{Multivariate zero-inflated models}

The effect of the independent variables on the parasitic infection intensity (egg/(oo)cyst counts per gram) was studied through the utilization of a zero-inflated negative binomial model [42] due to the excess of zero counts and overdispersion of the data. In this analysis the group of shepherd dogs were not included due to the limited number of samples examined (Additional file 2: Table S2). 


\section{Results}

\section{Dogs}

A total of 879 faecal samples from dogs were investigated for the presence of intestinal parasites. Of these samples, 278 were derived from shelter dogs, 529 from household dogs and 72 from shepherd dogs (Table 1). In total, $38.3 \%$ of dogs were found harbouring at least one intestinal parasite. Precisely $25.5 \%$ were harbouring one parasite, $8.9 \%$ two and the rest 3-6 different species. The overall infection rate was $25.2 \%$ (CI: 22.4-28.1) for Giardia spp.; 9.2\% (CI: 7.3-11.1) for Ancylostoma/ Uncinaria spp.; 7.6\% (CI: 5.9-9.4) for Toxocara spp.; 5.9\% (CI: 4.4-7.5) for Cryptosporidium spp.; 4.6\% (CI: 3.2-5.9) for Cystoisospora spp.; 2.7\% (1.7-3.8) for Toxascaris leonina; 1.7\% (CI: 0.9-2.6) for Capillaria spp.; $0.8 \%$ (CI: $0.2-1.4$ ) for taeniid eggs, $0.2 \%$ (CI: 0-0.5) for Dipylidium caninum; and 0.1\% (CI: 0-0.3) for Strongyloides stercoralis. The results for the different dog populations are shown in Table 1.
Among the different canine populations studied, shelter dogs had the highest infection rates. In particular, $62.9 \%$ of the shelter dogs were infected with at least one species of endoparasite compared to $51.4 \%$ of the shepherd dogs and $23.8 \%$ of the household dogs. According to the multivariate binary logistic model analysis, the odds ratio (OR) of Giardia infection was higher in shelter dogs than household dogs (11.24 times higher) and shepherd dogs (15.63 times higher). However, based on the multivariate zero-inflated model, among Giardia-infected individuals, household dogs had generally higher cyst counts than shelter dogs $(\mathrm{OR}=$ 1.602). Regarding Cryptosporidium, and according to the multivariate zero-inflated model, the odds ratio in favour of zero Cryptosporidium OPG for household dogs was 8.248 times higher than that for shelter dogs, suggesting that household dogs were less prone to Cryptosporidium infection than shelter dogs. However, Cryptosporidium-positive household dogs shed more

Table 1 Prevalence of intestinal parasites and factors associated with this prevalence in different dog populations. Percentages given for specific parasites refer to percentage of dogs that were found positive for an infection within a category of risk factor

\begin{tabular}{|c|c|c|c|c|c|}
\hline \multirow{2}{*}{$\begin{array}{l}\text { Dog } \\
\text { population }\end{array}$} & \multirow[t]{2}{*}{ Parasite species } & \multirow{2}{*}{$\begin{array}{l}\text { Prevalence (\%) } \\
(95 \% \mathrm{Cl})\end{array}$} & \multirow{2}{*}{$\begin{array}{l}\text { Infection intensity } \\
\text { Median }^{\mathrm{a}} \text { (Range) }\end{array}$} & \multicolumn{2}{|c|}{ History of diarrhoea } \\
\hline & & & & With diarrhoea & Without diarrhoea \\
\hline \multirow[t]{8}{*}{ Shelter } & All & $62.9(57.3-68.6)$ & & 46.0 & 54.0 \\
\hline & Giardia & $54.3(48.5-60.2)$ & $4,450(100-222,800)$ & 51.6 & 56.7 \\
\hline & Cryptosporidium & $14.7(10.6-18.9)$ & $200(100-1,400)$ & 7.8 & 20.7 \\
\hline & Toxocara spp. & $12.2(8.4-16.1)$ & $79(1-12,000)$ & 3.9 & 19.3 \\
\hline & T. leonina & $6.1(3.3-8.9)$ & $153(2-3,330)$ & 0.8 & 10.7 \\
\hline & Hookworms & $9.7(6.3-13.2)$ & $31(3-588)$ & 3.1 & 15.3 \\
\hline & Capillariidae & $0.7(0.0-1.7)$ & $1.5(1 \& 2)$ & 0.8 & 0.7 \\
\hline & Cystoisospora & $7.6(4.4-10.7)$ & $26(1-1,800)$ & 7.8 & 7.3 \\
\hline \multirow[t]{8}{*}{ Household } & All & $23.8(20.2-27.4)$ & & 25.5 & 74.5 \\
\hline & Giardia & $12.9(10.0-15.7)$ & $10,400(100-75,800)$ & 20.5 & 10.4 \\
\hline & Cryptosporidium & $1.9(0.7-3.1)$ & $300(100-40,300)$ & 4.5 & 1.3 \\
\hline & Toxocara spp. & $5.1(3.2-7.0)$ & $29(2-4,284)$ & 6.8 & 4.6 \\
\hline & T. leonina & $0.9(0.1-1.8)$ & $51(15-223)$ & 0 & 1.0 \\
\hline & Hookworms & $5.3(3.4-7.2)$ & $9(1-423)$ & 1.5 & 6.6 \\
\hline & Capillariidae & $1.9(0.7-3.1)$ & $4.5(1-1,246)$ & 2.3 & 1.8 \\
\hline & Cystoisospora & $2.5(1.1-3.8)$ & $7(1-8,400)$ & 3.8 & 2.0 \\
\hline \multirow[t]{9}{*}{ Shepherd } & All & $51.4(39.8-62.9)$ & & 0 & 100 \\
\hline & Giardia & $4.2(0.0-8.8)$ & $11,800(3,000-122,700)$ & 0 & 4.2 \\
\hline & Cryptosporidium & $1.4(0.0-4.1)$ & $1,200(1,200)$ & 0 & 1.4 \\
\hline & Toxocara spp. & $8.3(1.9-14.7)$ & $118.5(27-2543)$ & 0 & 8.3 \\
\hline & T. leonina & $2.8(0.0-6.6)$ & $282.5(109 \& 456)$ & 0 & 2.8 \\
\hline & Hookworms & $33.3(22.4-44.2)$ & $19(1-894)$ & 0 & 33.3 \\
\hline & Capillariidae & $4.2(0.0-8.8)$ & $20(1-36)$ & 0 & 4.2 \\
\hline & Cystoisospora & $8.3(1.9-14.7)$ & $3.5(1-41)$ & 0 & 8.3 \\
\hline & Taeniid & $6.9(1.1-12.8)$ & $16(3-72)$ & 0 & 6.9 \\
\hline
\end{tabular}


oocysts than infected shelter dogs $(\mathrm{OR}=12.182)$. No statistically significant correlations between infection with the other parasites and their living conditions were detected in both models (Table 2).

The mean age of the sampled dogs was approximately 3 years (39.5 months $\pm 41.8, \mathrm{SD})$. The majority of the dogs were adults ( $\geq 12$ months, $n=642)$, while 229 of them were younger than 12 months and 8 were of unspecified age. There was a significant correlation between age and Giardia infection (Fig. 2) and between age and T. leonina infection intensity. According to the multivariate binary logistic model analysis, as age increased by one month, the odds of detecting Giardia cysts decreased by $1.9 \%=[(0.981-1) \times 100]$ which is also confirmed by the multivariate zero-inflated model, according which the odds of absence of Giardia cysts are increased by one unit increase of age. Similarly, according to the multivariate zero-inflated model, as age increased by one month, the odds of detecting T. leonina eggs decreases by $7 \%=[(0.93-1) \times 100]$. Regarding the other parasites studied, their correlation with age was not statistically significant.

Of the dogs which had a history of recent diarrhoea, $43.1 \%$ were positive for at least one intestinal parasite. However, faecal consistency was not significantly associated with parasitic infection. The statistical analyses showed that signs of diarrhoea (based on faeces consistency) were significantly more often present in younger animals $(U=100,667, P=<0.001)$. Moreover, there was a statistically significant association between the factors "recent record of diarrhoea" and "live with other animals", $\left(\chi_{(6, N=1138)}^{2}=29.495, P=<0.001\right)$.

On average, all of the dogs sampled received 2.1 anthelmintic treatments/year (range 0-6). The arithmetic mean of anthelmintic treatments/year was 2.3 for household dogs, 2.2 for shelter dogs and 0.5 for shepherd dogs. Information about anthelmintic treatments was not defined in 48 cases (5.5\%). The frequency of antiparasitic treatment was also associated with diarrhoea and more specifically, the effect of the odds of one treatment per year increase resulted in a decrease by 0.828 times in the trace of "recent record of diarrhoea", implying diarrhoea to be caused by parasite infestation. However, the number of antiparasitic treatments/year received was not statistically associated with parasitic infection.

The risk analyses of all the other factors which were evaluated in this study, such as the gender of the animals, their living conditions (indoors/outdoors), the type of food, and recent travelling, showed no statistically significant correlation with parasitic infection. Since almost all shelter dogs had access to the external environment and the shepherd dogs were also living outside, the risk factor "living indoors/outdoors" was assessed only for household dogs. The risk factor "recent travelling" was also not analysed since only $4.2 \%$ of the dogs had been travelling during the last months before sampling, including within counties. The same applied for the "type of food" factor, since the majority of the dogs were

Table 2 Prevalence of intestinal parasites and factors associated with this prevalence in different cat populations. Percentages given for specific parasites refer to percentage of cats that were found positive for an infection within a category of risk factor

\begin{tabular}{|c|c|c|c|c|c|}
\hline \multirow{2}{*}{$\begin{array}{l}\text { Cat } \\
\text { population }\end{array}$} & \multirow[t]{2}{*}{ Parasite species } & \multirow{2}{*}{$\begin{array}{l}\text { Prevalence } \\
\text { (\%)(95\% Cl) }\end{array}$} & \multirow{2}{*}{$\begin{array}{l}\text { Infection intensity } \\
\text { Medianª (Range) }\end{array}$} & \multicolumn{2}{|c|}{ History of diarrhoea } \\
\hline & & & & With diarrhoea & Without diarrhoea \\
\hline \multirow[t]{8}{*}{ Shelter } & All & $55.9(43.3-68.6)$ & & 15.3 & 84.7 \\
\hline & Giardia & $39.0(26.5-51.4)$ & $5,700(100-700)$ & 33.3 & 40.0 \\
\hline & Cryptosporidium & $11.9(3.6-20.1)$ & $100(100-700)$ & 22.2 & 10.0 \\
\hline & Toxocara spp. & $10.2(2.5-7.9)$ & $3(1-63)$ & 22.2 & 8.0 \\
\hline & T. leonina & 0 & 0 & 0 & 0 \\
\hline & Hookworms & $5.1(-0.5-10.7)$ & $7(5-22)$ & 0.0 & 6.0 \\
\hline & Capillariidae & $5.1(0.0-10.7)$ & $38(17-84)$ & 0.0 & 6.0 \\
\hline & Cystoisospora & $8.5(1.4-15.6)$ & $42(2-2,330)$ & 0.0 & 10.0 \\
\hline \multirow[t]{8}{*}{ Household } & All & $33.2(26.7-39.6)$ & & 35.9 & 64.1 \\
\hline & Giardia & $15.6(10.6-20.6)$ & $5,800(100-248,100)$ & 16.4 & 13.1 \\
\hline & Cryptosporidium & $5.4(2.3-8.5)$ & $400(100-1,800)$ & 5.5 & 4.6 \\
\hline & Toxocara spp. & $7.8(4.1-11.5)$ & $278.5(1-2,500)$ & 2.7 & 10.0 \\
\hline & T. leonina & 0 & 0 & 0 & 0 \\
\hline & Hookworms & $8.3(4.5-12.1)$ & $72(1-523)$ & 5.5 & 10.0 \\
\hline & Capillariidae & $3.9(1.3-6.6)$ & $8.5(1-1,161)$ & 4.1 & 3.8 \\
\hline & Cystoisospora & $9.8(5.7-13.8)$ & $84.5(1-6,114)$ & 8.2 & 9.2 \\
\hline
\end{tabular}




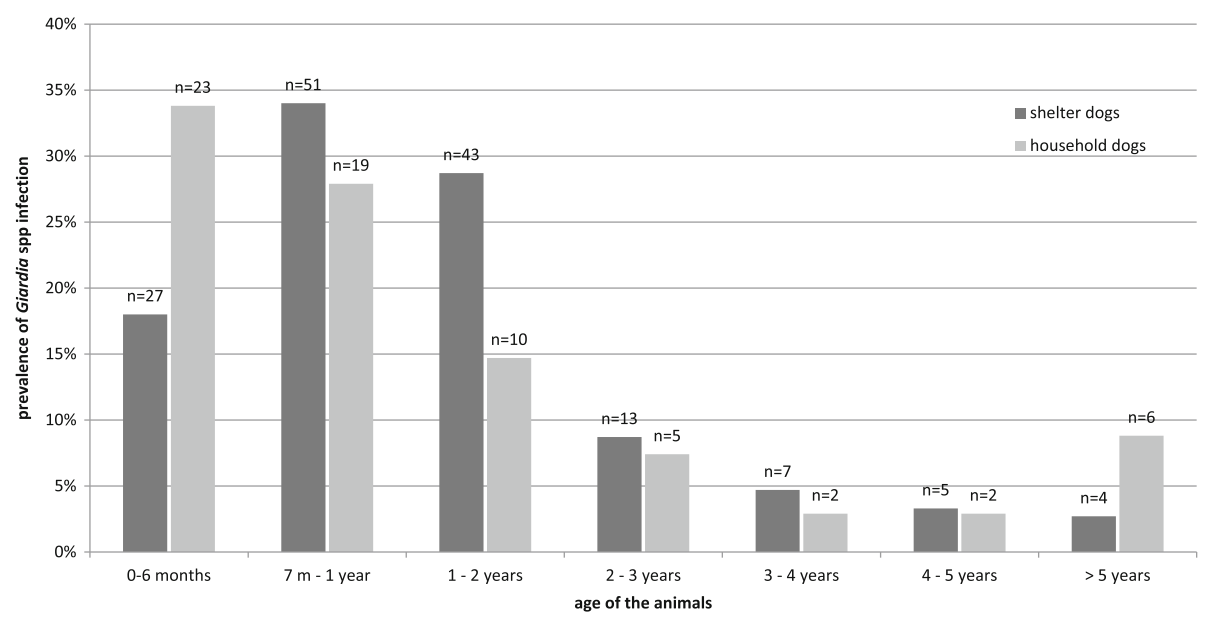

Fig. 2 Prevalence of Giardia spp. in different dog populations and different age groups

eating industrial/cooked food and only 28 were fed with raw meat/offal, $64 \%$ of these being shepherd dogs.

Giardia spp. was the most prevalent parasite in all dogs $(25.2 \%)$ and also in shelter (54.3\%) and household (12.9\%) dogs in particular. The range of the cysts being shed by the infected animals varied from 100 to 275,800 cysts per gram of faeces with 6,855 cysts shed on average. In the samples derived from shelter and household dogs, the dog-specific assemblages $\mathrm{C}$ and $\mathrm{D}$ were dominating, either alone $(n=72)$ or in mixed infections $(n=15)$. A limited number of dogs were infected with assemblage A $(n=2)$, assemblage AI $(n=1)$, assemblage AII $(n=1)$ or a mixture of A with C or D $(n=5)$ or BIV-like and C $(n=1)$ (Table 3). Regarding shepherd dogs, no positive PCR products were sequenced successfully. Multilocus genotyping was performed from one dog sample which was classified as sub-assemblage AI using 3 genetic loci (bg, TPIGEN and GDH). Alignment analysis of the isolate showed $100 \%$ homology when compared to reference sequences A5 for bg; A1 for TPIGEN and A1 for GDH [39], resulting in multilocus genotype MLGA1 [43].

The PCR results for Cryptosporidium positive samples showed that the HSP70 gene amplified $23.6 \%$ of the samples, whereas the $18 \mathrm{~S}$ rDNA gene amplified 5.6\%. Sequencing revealed the presence of Cryptosporidium canis in 2 household dogs and C. scrofarum in a shelter dog.

\section{Cats}

In total, 264 faecal samples from cats were collected; 59 samples from shelters and 205 from owned cats. Unfortunately, it was not possible to reach the target of 385 shelter cats. Overall, $38.1 \%$ of the cats were harbouring at least one intestinal parasite. Precisely $26.4 \%$ were harbouring one parasite, $8.3 \%$ two and the rest 3-4 different species. The prevalence was 20.5\% (CI: 15.6-25.3) for Giardia spp.; 9.5\% (CI: 5.9-13.0) for Cystoisospora spp.;
8.3\% (CI: 5.0-11.7) for Toxocara spp.; 7.6\% (CI: 4.4-10.8) for Ancylostoma/Uncinaria spp.; 6.8\% (CI: 3.8-9.9) for Cryptosporidium spp.; 4.2\% (CI: 1.8-6.6) for Capillaria spp.; 0.8\% (CI: 0.0-1.8) for taeniid eggs; and 0.4\% (CI: 01.1) for Hammondia/Toxoplasma. The results among different feline populations are shown in Table 4.

The mean age of the sampled cats was 3.4 years (40.8 months \pm 48.9 , SD). The majority of the cats were adults ( $\geq 12$ months, $n=161$ ), while 97 of them were younger than 12 months and 6 were of unspecified age.

Among the different feline populations studied, shelter cats had the highest infection rates. Specifically, $55.9 \%$ of the shelter cats were infected with at least one species of intestinal parasite compared to $33.2 \%$ of the household cats. However, infection rates of the different parasites were not statistically different between different cat populations.

Of the cats which had a history of diarrhoea (30.9\%), $32.9 \%$ were infected with at least one parasite. On average, all cats sampled received 2.3 anthelmintic treatments/year (range 0-6). The mean number of anthelmintic treatments/year was 1.9 for household cats and 2.7 for shelter cats. Information about anthelmintic treatments was unknown in one case. Only $1.5 \%$ of the cats had been travelling during the last months including within counties. No significant associations were found between parasite infections and risk factors or between parasite infections and diarrhoea.

Giardia spp. was the most prevalent parasite (20.5\%), both in shelter cats (39.0\%) and household cats (15.6\%). When targeting the $18 \mathrm{~S}$ rRNA gene, assemblage A was identified in 10 cat samples. In 6 of these samples, no amplification was obtained with the other genes, while in 4 samples only assemblage $\mathrm{F}$ was detected in at least one of the other loci. Assemblage F was also found alone in 2 samples. Also, in two different cases, the typing 
Table 3 Genotyping results of samples from dogs infected by Giardia duodenalis (at all different loci)

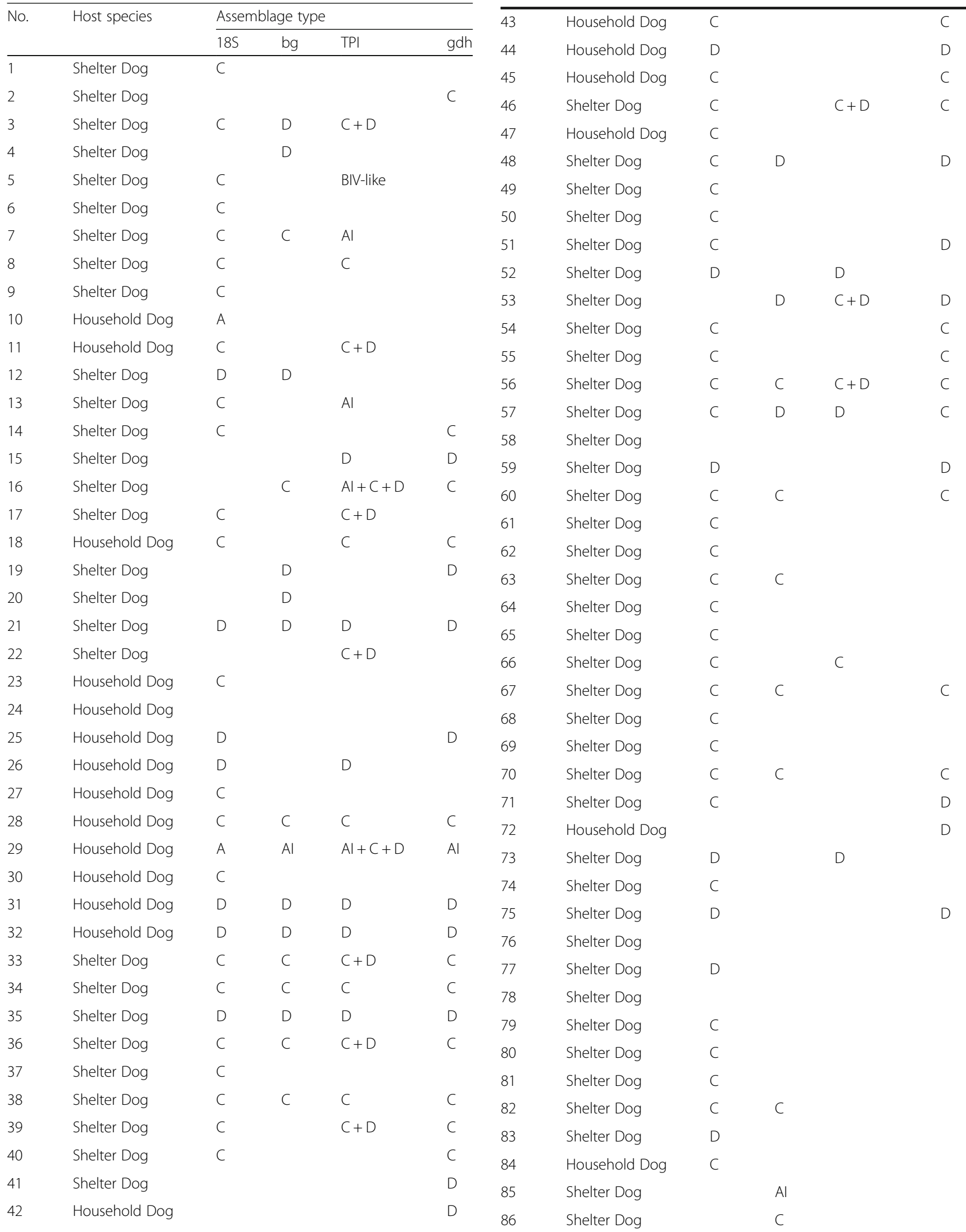

Table 3 Genotyping results of samples from dogs infected by

Giardia duodenalis (at all different loci) (Continued)

D

(1)

(1)

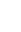


Table 3 Genotyping results of samples from dogs infected by Giardia duodenalis (at all different loci) (Continued)

\begin{tabular}{|c|c|c|c|c|c|}
\hline 87 & Household Dog & & $C$ & $C$ & $C$ \\
\hline 88 & Household Dog & & & & \\
\hline 89 & Household Dog & & & & \\
\hline 90 & Household Dog & & $D$ & $C+D$ & \\
\hline 91 & Household Dog & & & $\mathrm{D}$ & \\
\hline 92 & Shelter Dog & & & All & \\
\hline 93 & Shelter Dog & A & & & \\
\hline 94 & Shelter Dog & $\mathrm{D}$ & & & \\
\hline 95 & Shelter Dog & $C$ & & & \\
\hline 96 & Shelter Dog & & & & $\mathrm{D}$ \\
\hline 97 & Household Dog & & & & C \\
\hline 98 & Shelter Dog & & & & $\mathrm{D}$ \\
\hline 99 & Shelter Dog & & & & \\
\hline 100 & Shelter Dog & & & $\mathrm{D}$ & \\
\hline 101 & Shelter Dog & & & & \\
\hline 102 & Shelter Dog & & & & \\
\hline 103 & Household Dog & & & D & \\
\hline 104 & Household Dog & & & $\mathrm{D}$ & $\mathrm{D}$ \\
\hline 105 & Household Dog & & & $\mathrm{D}$ & All \\
\hline 106 & Household Dog & & & & $C$ \\
\hline
\end{tabular}

Table 4 Genotyping results of samples from cats infected by Giardia duodenalis (at all different loci)

\begin{tabular}{|c|c|c|c|c|c|}
\hline \multirow[t]{2}{*}{ No. } & \multirow[t]{2}{*}{ Host species } & \multicolumn{4}{|c|}{ Assemblage type } \\
\hline & & $18 \mathrm{~S}$ & $\mathrm{bg}$ & TPI & gdh \\
\hline 1 & Shelter Cat & $A$ & & & \\
\hline 2 & Shelter Cat & A & & & \\
\hline 3 & Shelter Cat & A & $\mathrm{F}$ & $\mathrm{F}$ & \\
\hline 4 & Shelter Cat & A & & & \\
\hline 5 & Shelter Cat & A & & & \\
\hline 6 & Household Cat & & $\mathrm{F}$ & $\mathrm{F}$ & $\mathrm{F}$ \\
\hline 7 & Shelter Cat & & & BIV-like & \\
\hline 8 & Household Cat & A & $\mathrm{F}$ & & $\mathrm{F}$ \\
\hline 9 & Household Cat & & & & \\
\hline 10 & Household Cat & A & $\mathrm{F}$ & $\mathrm{F}$ & $F$ \\
\hline 11 & Household Cat & A & $\mathrm{F}$ & $\mathrm{F}$ & $\mathrm{F}$ \\
\hline 12 & Household Cat & A & & & \\
\hline 13 & Household Cat & A & & & \\
\hline 14 & Household Cat & & & $\mathrm{F}$ & \\
\hline 15 & Household Cat & & & & no result \\
\hline 16 & Household Cat & & & & C \\
\hline
\end{tabular}

revealed the presence of assemblage BIV-like $(n=1)$ or the dog specific assemblage $C(n=1)$ (Table 4$)$.

Genotyping of Cryptosporidium positive samples showed the presence of the feline specific species Cryptosporidium felis $(n=4)$.

\section{Discussion}

The infection rates of intestinal parasites detected in this study, revealed a high prevalence of parasitic infections (38.2\%) and the presence of different species of endoparasites in both dogs and cats. These infection rates were equally distributed within animal species $(38.3 \%$ for dogs and $38.1 \%$ for cats) involved in the study. With the exception of shepherd dogs, Giardia spp. was the most prevalent parasite detected in the dog and cat populations followed by significant prevalences of ascarids, hookworms and taeniid infections. These results are also reported in other studies which consider Giardia the most common enteric parasite of dogs and cats in developed countries [2, 3, 23, 28, 44-48]. In shepherd dogs, hookworms were the most prevalent parasite species detected.

Among the targets of this study was to investigate the potential effect of animal lifestyle to parasitism so animals living in households, shelters or farms were included. The results showed that more than half of the shelter dogs and cats were infected with at least one species of endoparasite, which was more or less expected, taking into consideration the less hygienic conditions that those animal are living in combined with a high population density that usually exists in shelters. A high level of parasitism has been previously reported in shelter dogs $[3,5,22,24]$ while in shelter cats the prevalence observed in other studies was lower $[49,50]$.

More than half of the shepherd dogs (51.4\%) were positive for at least one species of intestinal parasite. The infection rate of intestinal parasites estimated in shepherd dogs in this study was higher than in a previous record from Greece (26.0\%) [27]. Such differences are expected in cross-sectional studies especially given time and region differences. However, our results were in agreement with a study conducted in farm dogs in Portugal (57.4\%) [51]. Shepherd/farm dogs often receive less veterinary care and preventive treatments. Compared to a general average of more than 2 anthelmintic treatments per year, shepherd dogs in our study received only 0.5 treatments per year.

Although the prevalence of intestinal parasites in household dogs was lower than in shelters, although not statistically significant for many species, the percentage of individuals infected was still noteworthy (23.8\%). In similar studies conducted in Italy the prevalence of intestinal parasites in household dogs was even higher, reaching $57.0 \%$ of the animals $[6,23]$. In our study there was no difference in the risk of infection between dogs 
living in an apartment with no access to a yard or a garden and dogs living in a house with access to outdoors. A reason for that could be that even dogs that are kept permanently indoors are regularly being walked by their owners in public places getting in close contact with other dogs (including stray ones) or their contaminated faeces. Similar results were recorded in the household cats studied, but this was probably due to the fact that the majority of them also live partially outdoors. The parasitism reported in household cats in this study is in agreement with the infection rates reported in Austria, Belgium, the Netherlands, France, Hungary, Italy, Romania and Spain $[6,8,21]$.

Although both household and shelter dogs received regular anthelmintic treatments (i.e. an average of 2.3 for household dogs and 2.2 for shelter dogs per year), this seemed not to control parasitism efficiently. This is in agreement with the general recommendation by ESCCAP for roundworms in which it is suggested that annual or twice yearly treatments do not have a significant impact on the prevalence of patent infections within a population, and therefore a treatment frequency of at least 4 times per year is recommended (Worm Control in Dogs and Cats - ESCCAP, www.esccap.org). Recent modeling indicated that the environmental Toxocara contamination by dogs can only be reduced significantly if compliance to the four times a year treatment advice is sufficiently high $(90 \%)$ or if at least half of the dog owners consistently remove their dog's faeces [52]. In cats, the frequency of anthelmintic treatment differed between categories, with shelter cats being more frequently treated (i.e. an average of 1.9 for household cats and 2.7 for shelter cats per year). This could be explained by a misconception of the cat owners that indoor cats do not need preventive treatments [53].

Despite the high prevalence of parasitic infections, most animals were healthy with no obvious signs of suffering probably due to the low parasitic burden, as at least suggested by the low number of egg/(oo)cyst output recorded in most cases (even if usually there is not a clear correlation between numbers of eggs/(oo-)cysts and clinical signs). It was not statistically proven that recent records of diarrhoea were correlated to parasitism as also shown previously $[54,55]$ although there was evidence that anthelmintic treatment had a positive effect on reducing such records. A supporting argument for the absence of clinical disease could be that the majority of animals were adults at the time of sampling. Young animals are more sensitive to parasitism [56] but although in this study there was a tendency of older animals ( $>2$ year-old dogs and $>1$ year-old cats) to be less infected, this was not statistically significant for most parasites. The only statistically proven facts were that the chance to get infected by Giardia spp. and the infection intensity of $T$. leonina was negatively correlated to age in dogs.

Given the high prevalence and the potential zoonotic importance, Giardia and Cryptosporidium positive samples were further investigated by PCR and sequencing of the positive PCR products. In dogs, the host-specific assemblages $\mathrm{C}$ and $\mathrm{D}$ dominated, which has been described before in various studies [23, 24, 36, 57-62]. Few dogs were (co)- infected with assemblage $\mathrm{A}$, and the majority of these were identified as sub-assemblage AI. Subassemblage AI is frequently found in animals, while humans are most frequently infected with sub-assemblage AII $[63,64]$. The sequence analysis in one G. duodenalis sample further revealed a multilocus genotype (MLG) which was previously described in calves in China [43]. Together, these results suggest that there is no significant risk for zoonotic transmission of Giardia infections from dogs in Crete.

In cats, the genotyping results seemed to indicate the dominance of the potentially zoonotic assemblage A in shelter animals and the co-infection of assemblages $\mathrm{A}$ and the feline specific assemblage $\mathrm{F}$ in household cats. However, the zoonotic assemblage A was identified only at the $18 \mathrm{~S}$ rDNA locus, while only assemblage $\mathrm{F}$ was identified at the other loci. Since no distinction could be made between assemblages $\mathrm{A}$ and $\mathrm{F}$ in the amplified region of the conserved rRNA $18 \mathrm{~S}$ gene, it cannot be excluded that (some of) the samples that were amplified with rDNA $18 \mathrm{~S}$ gene were assemblage $\mathrm{F}$ instead of $\mathrm{A}$. Therefore, no conclusion can be drawn on the zoonotic risk associated with Giardia infections in cats.

Regarding Cryptosporidium, the dog specific C. canis was identified in only two household dogs and the pig specific C. scrofarum in one shelter dog. Cryptosporidium canis has been also detected in household dogs in other studies $[48,65,66]$ and isolated in humans, mainly children and immunocomprimised individuals in developing countries $[67,68]$, suggesting its potential public health impact. To our knowledge, this is the first case of $C$. scrofarum infection reported in a dog. Since keeping backyard pigs is quite a common practice in the area, it is possible that this dog ingested the oocysts before being transferred to the shelter. In such a scenario this could be a case of pseudoparasitism, given that this dog was 2.5 month-old and only recently introduced to the shelter. In cats, sequencing was not efficient; nevertheless, it revealed the presence of the feline-specific $C$. felis. Since our genotyping results revealed the presence of host-specific Cryptosporidium species in both dogs and cats which have been implicated in very few human infections and mainly in developing countries, we could suggest that the zoonotic potential of Cryptosporidium from dogs in the study area is low.

Apart from Giardia and Cryptosporidium, ascarids, hookworms and taeniids are also considered to be 
zoonotic [13, 69-72]. The two major ascarid species $T$. canis and T. cati (to a lesser extent) are responsible for human infections $[13,72]$. In our study the prevalence of Toxocara spp. in dogs and cats was 7.6 and 8.3\%, respectively. In dogs, we characterised all Toxocara eggs found as Toxocara spp. since those infections were only microscopically diagnosed and as previously suggested they could either belong to $T$. canis or $T$. cati since coprophagy is not unusual for dogs and the presence of $T$. cati eggs in dog faeces might in fact relate to pseudoparasitism $[73,74]$. The infection rates found in the present study are similar to those reported in Europe which vary from 3.5 to $34.0 \%$ for $T$. canis in dogs from different epidemiological environments and from 7.2 to $76.0 \%$ for $T$. cati in cats $[8,10,18,52,75-79]$. The Toxocara infection was high, especially in shelter dogs and cats, as also reported before [24, 80, 81]. Although mainly T. canis is considered responsible for human toxocarosis [82], the role of $T$. cati in human toxocarosis should not be underestimated [82-84]. In Greece, toxocarosis in humans has not been studied extensively since published data are restricted only to some sporadic cases $[85,86]$ and one study regarding the seroprevalence of $T$. canis in children [87]. Our results combined to all European studies presented above strongly suggest that more information is needed.

Hookworm infection rates were $9.2 \%$ in dogs and $7.6 \%$ in cats. The highest infection rates of hookworms were identified in shepherd dogs (33.3\%) similar to the study of Mateus et al. [51] in Portugal (31.0\%). Since different hookworm species were not differentiated, the zoonotic risk associated with hookworm infections could not be determined.

The detection of taeniid eggs in shepherd dogs is worth mentioning. Unlike shelter and household dogs, shepherd dogs seem to be more prone to taeniid infection, which possibly is due to the frequent consumption of raw meat and carcasses [2, 88]. Echinococcosis is still endemic in Greece with a high prevalence reported in livestock [89-91]. However, there are no recent reports regarding the prevalence of taeniids in dogs. Taking into consideration our results in combination with the high prevalence of $E$. granulosus in livestock, which is transmitted through dogs, we could assume that shepherd dogs in Greece could be a reservoir for human infections.

\section{Conclusions}

In conclusion, we have recorded high levels of (multi)parasitism in both dogs and cats in the study area. Most of the animals were harbouring different species of parasites sometimes in high numbers according to the egg/ (oo)cyst counts. This is a proof that those parasites are greatly abundant within animal populations regardless of lifestyle. Thus, the results of our study, stress the need for better anthelmintic control schemes in dogs and cats tailored to their individual needs in order to safeguard animal and public health.

\section{Additional files}

Additional file 1: Examples of alignments analyzed (different target genes) in both dogs and cats. (ZIP $3 \mathrm{~kb}$ )

Additional file 2: Table S1. Binary logistic model for Giardia spp. infection rate in dogs. Table $\mathbf{S 2}$. Zero-inflation negative binomial model for parasite infection intensity in dog samples. (DOCX $17 \mathrm{~kb}$ )

\section{Aknowledgements}

This work is a part of a PhD scholarship funded by the Greek State Scholarships Foundation. The authors will also like to thank all the veterinarians, the shelter owners, Dr Alexandros Stefanakis, Mr Anastasios Anastasiades and other colleagues in Crete who contributed in this study.

\section{Funding}

This work is a part of a PhD scholarship funded by the Greek State Scholarships Foundation.

Availability of data and materials

All data generated or analysed during this study are included in the article.

\section{Authors' contributions}

This study was conducted by DK as part of her PhD thesis. Also, DK participated in the data collection and analysis and developed the first draft of the manuscript. All other authors played a role in data collection and analysis, and interpretation of findings (EC, DA, PL, NV, SC and SS). All authors read and approved the final manuscript.

\section{Competing interests}

The authors declare that they have no competing interests.

\section{Consent for publication}

Not applicable.

\section{Ethics approval}

The study was carried out in compliance with the national animal welfare regulations. Diagnostic veterinary procedures are not within the context of relevant EU legislation for animal experimentations (Directive 86/609/EC) and may be performed in order to diagnose animal diseases and improve animal welfare. Samples were collected by registered veterinarians who ensured owners consent and caused no suffering.

Received: 4 September 2016 Accepted: 18 January 2017

Published online: 25 January 2017

\section{References}

1. Capelli G, Paoletti B, lorio R, Frangipane di Regalbono A, Pietrobelli M, Bianciardi P, Giangaspero A. Prevalence of Giardia spp. in dogs and humans in nothern and central Italy. Parasitol Res. 2003;90:S154-5.

2. Palmer CS, Thompson RCA, Traub RJ, Rees R, Robertson ID. National study of the intestinal parasites of dogs and cats in Australia. Vet Parasitol. 2008;151:181-90.

3. Claerebout E, Casaert S, Dalemans AC, De Wilde N, Levecke B, Vercruysse J, Geurden T. Giardia and other intestinal parasites in different dog populations in Nothern Belgium. Vet Parasitol. 2009;161:41-6.

4. Joffe D, Van Niekerk D, Gagne F, Gilleard J, Kutz S, Lobingier R. The prevalence of intestinal parasites in dogs and cats in Calgary, Alberta. Can Vet J. 2011;52:1323-8.

5. Ortuno A, Castella J. Intestinal parasites in shelter dogs and risk factors associated with the facility and its management. Isr J Vet Med. 2011;66:103-7.

6. Riggio F, Mannella R, Ariti G, Perrucci S. Intestinal and lung parasites in owned dogs and cats from Central Italy. Vet Parasitol. 2013;193:78-84.

7. Itoh N, Kanai K, Kimura Y, Chikazawa S, Hori Y, Hoshi F. Prevalence of intestinal parasites in breeding kennel dogs in Japan. Parasitol Res. 2015;114(3):1221-4. 
8. Nijsse R, Ploeger HW, Wagenaar JA, Mughini-Gras L. Prevalence and risk factors for patent Toxocara infections in cats and cat owners' attitude towards deworming. Parasitol Res. 2016;115(12):4519-25.

9. Pereira A, Martins A, Brancal H, Vilhena H, Silva P, Pimenta P, Diz-Lopes D, Neves N, Coimbra M, Alves AC, Cardoso L, Maia C. Parasitic zoonoses associated with dogs and cats: a survey of Portuguese pet owners' awareness and deworming practices. Parasit Vectors. 2016;9:245.

10. Lee ACY, Shantz PM, Kazacos KR, Montgomery SP, Bowman DD. Epidemiologic and zoonotic aspects of ascarid infection of dogs and cats. Trends Parasitol. 2010:26:155-61.

11. Deplazes P, Van Knapen F, Schweiger A, Overgaauw PAM. Role of pet dogs and cats in the transmission of helminthic zoonoses in Europe, with a focus on echinococcosis and toxocarosis. Vet Parasitol. 2011;182:41-53.

12. Chen J, Xu MJ, Zhou DH, Song HQ, Wang CR, Zhu XQ. Canine and feline parasitic zoonoses in China. Parasit Vectors. 2012;5:152.

13. Macpherson CNL. The epidemiology and public health importance of toxocariasis: a zoonosis of global importance. Int J Parasitol. 2013;43:999-1008.

14. Sutherst RW. Global change and human vulnerability to vector-borne diseases. Clin Microbiol Rev. 2004;17:136-73.

15. Tabachnick WJ. Challenges in predicting climate and environmental effects on vector-borne disease episystems in a changing world. J Exp Biol. 2010;213:946-54.

16. Jones KE, Patel NG, Levy MA, Storeygard A, Balk D, Gittleman JL, Daszak P. Global trends in emerging infectious diseases. Nature. 2008;451:990-4.

17. Otranto D, Eberhard ML. Zoonotic helminths affecting the human eye. Parasit Vectors. 2011;4:41.

18. Dubna S, Langrova I, Napravnik J, Jankovska I, Vadlejch J, Pekar S, Fechtner J. The prevalence of intestinal parasites in dogs from Prague, rural areas, and shelters of the Czech Republic. Vet Parasitol. 2007;145:120-8.

19. Martinez-Moreno FJ, Hernandez S, Lopez-Cobos E, Becerra C, Acosta I, Martinez-Moreno A. Estimation of canine intestinal parasites in Cordoba (Spain) and their risk to public health. Vet Parasitol. 2007;143:7-13.

20. Overgaauw PAM, van Zutphen L, Hoek D, Yaya FO, Roelfsema J, Pinelli E, et al. Zoonotic parasites in fecal samples and fur from dogs and cats in the Netherlands. Vet Parasitol. 2009;163:115-22.

21. Beugnet F, Bourdeau P, Chalvet-Monfray K, Cozma V, Farkas R, Guillot J, et al. Parasites of domestic owned cats in Europe: co-infestations and risk factors. Parasit Vectors. 2014;7:291.

22. Ortuno A, Scorza V, Castella J, Lappin M. Prevalence of intestinal parasites in shelter and hunting dogs in Catalonia, Northeastern Spain. Vet J. 2014; 199:465-7.

23. Zanzani SA, Gazzonis AL, Scarpa P, Berrilli F, Manfredi MT. Intestinal parasites of owned dogs and cats from metropolitan and micropolitan areas: prevalence, zoonotic risks, and pet owner awareness in nothern Italy. BioMed Res Int. 2014;2014:696508. doi:10.1155/2014/696508.

24. Simonato G, Frangipane di Regalbono A, Cassini R, Traversa D, Beraldo P, Tessarin C, Pietrobelli M. Copromicroscopic and molecular investigations on intestinal parasites in kenneled dogs. Parasitol Res. 2015;114:1963-70.

25. Hamnes IS, Gjerde BK, Robertson LJ. A longitudinal study on the occurrence of Cryptosporidium and Giardia in dogs during their first year of life. Acta Vet Scand. 2007:49:22.

26. Leonhard S, Pfister K, Beelitz P, Wielinga C, Thompson RCA. The molecular characterization of Giardia from dogs in southern Germany. Vet Parasitol. 2007;150:33-8

27. Papazahariadou M, Founta A, Papadopoulos E, Chliounakis S, AntoniadouSotiriadou K, Theodorides Y. Gastrointestinal parasites of shepherd and hunting dogs in the Serres Prefecture, Northern Greece. Vet Parasitol. 2007; 148:170-3.

28. Barutzki D, Schaper R. Results of parasitological examinations of faecal samples from cats and dogs in Germany between 2003 and 2010. Parasitol Res. 2011:109:S45-60.

29. Rinaldi L, Coles GC, Maurelli MP, Musella V, Cringoli G. Calibration and diagnostic accuracy of simple flotation, McMaster and Flotac for parasite egg counts in sheep. Vet Parasitol. 2011;177:345-52.

30. MAFF. Manual of veterinary parasitology laboratory techniques. Ministry of Agriculture, Fisheries and Food. London: Her Majesty's Stationery Office; 1986

31. Kostopoulou D, Casaert S, Tzanidakis N, van Doorn D, Demeler J, von SamsonHimmelstjerna $G$, et al. The occurrence and genetic characterization of Cryptosporidium and Giardia species in foals in Belgium, The Netherlands, Germany and Greece. Vet Parasitol. 2015;211(3-4):170-4.
32. Geurden T, Berkvens D, Casaert S, Vercruysse J, Claerebout E. A Bayesian evaluation of three diagnostic assays for the detection of Giardia duodenalis in symptomatic and asymptomatic dogs. Vet Parasitol. 2008;157(1-2):14-20.

33. Morgan UM, Monis PT, Xiao L, Limor J, Sulaiman I, Raidal S, et al. Molecular and phylogenetic characterization of Cryptosporidium from birds. Int J Parasitol. 2001;31:289-96.

34. Xiao L, Singh A, Limor J, Graczyk TK, Gradus S, Lal AA. Molecular characterization of Cryptosporidium oocysts in samples of raw surface water and wastewater. Appl Environ Microbiol. 2001;6:1097-101.

35. Hopkins RM, Meloni BP, Groth DM, Wetherall JD, Reynoldson JA, Thompson RCA. Ribosomal RNA sequencing reveals differences between the genotypes of Giardia isolates recovered from humans and dogs living in the same locality. J Parasitol. 1997;83:44-51.

36. Lalle M, Pozio E, Capelli G, Bruschi F, Crotti D, Caccio SM. Genetic heterogeneity at the beta-giardin locus among human and animal isolates of Giardia duodenalis and identification of potentially zoonotic subgenotypes. Int J Parasitol. 2005;35:207-13.

37. Geurden T, Geldhof P, Levecke B, Martens C, Berkvens D, Casaert S, et al. Mixed Giardia duodenalis assemblage A and E infections in calves. Int J Parasitol. 2008;38:259-64.

38. Read CM, Monis PT, Thompson RC. Discrimination of all genotypes of Giardia duodenalis at the glutamate dehydrogenase locus using PCR-RFLP. Infect Genet Evol. 2004;4:125-30.

39. Caccio SM, Beck R, Lalle M, Marinculic A, Pozio E. Multilocus genotyping of Giardia duodenalis reveals striking differences between assemblages $\mathrm{A}$ and $\mathrm{B}$. Int J Parasitol. 2008:38:1523-31.

40. R Core Team. R: A language and environment for statistical computing. Vienna, Austria: R Foundation for Statistical Computing; 2013.

41. Jackman S. pscl: Classes and methods for R developed in the political science computational laboratory, Stanford University. Department of Political Science, Stanford University, Stanford, California. R package version 0.95, URL http://CRAN.R-project.org/package=pscl. Accessed 25 Aug 2016.

42. Lambert D. Zero-inflated Poisson regression, with an application to defects in manufacturing. Technometrics. 1992;34:1-14.

43. Wang XT, Wang RJ, Ren GJ, Yu ZQ, Zhang LX, Zhang SY, et al. Multilocus genotyping of Giardia duodenalis and Enterocytozoon bieneusi in dairy and native beef (Qinchuan) calves in Shaanxi province, northwestern China. Parasitol Res. 2016:115:1355-61.

44. Thompson RC, Palmer CS, O'Handley R. The public health and clinical significance of Giardia and Cryptosporidium in domestic animals. Vet J. 2008;177:18-25

45. Scaramozzino P, Di Cave D, Berrilli F, D'Orazi CD, Spaziani A, Mazzanti S, et al. A study of the prevalence and genotypes of Giardia duodenalis infecting kenneled dogs. Vet J. 2009;182:231-4.

46. Ballweber LR, Xiao L, Bowman DD, Kahn G, Cama VA. Giardiasis in dogs and cats: update on epidemiology and public health significance. Trends Parasitol. 2010;26:180-9

47. Polak KC, Levy JK, Crawford PC, Leutenegger CM, Moriello KA. Infectious diseases in large-scale cat hoarding investigations. Vet J. 2014;201:189-95.

48. Osman M, Bories J, El Safadi D, Poirel M, Gantois N, Benamrouz-Vanneste S, et al. Prevalence and genetic diversity of the intestinal parasites Blastocystis sp. and Cryptosporidium spp. in household dogs in France and evaluation of zoonotic transmission risk. Vet Parasitol. 2015;214:167-70.

49. Becker AC, Rohen M, Epe C, Schnieder T. Prevalence of endoparasites in stray and fostered dogs and cats in Northern Germany. Parasitol Res. 2012;111:849-57.

50. Ito $Y$, Itoh N, Kimura Y, Kanai K. Prevalence of intestinal parasites in breeding cattery cats in Japan. J Feline Med Surq. 2016;18:834-7.

51. Mateus TL, Castro A, Ribeiro JN, Vieira-Pinto M. Multiple zoonotic parasites identified in dog feces collected in Ponte de Lima, Portugal - A potential threat to human health. Int J Environ Res Public Health. 2014;11:9050-67.

52. Nijsse R, Mughini-Gras L, Wagenaar JA, Franssen F, Ploeger HW. Environmental contamination with Toxocara eggs: a quantitative approach to estimate the relative contributions of dogs, cats and foxes, and to assess the efficacy of advised interventions in dogs. Parasit Vectors. 2015;8:397.

53. Matos M, Alho AM, Owen SP, Nunes T. Parasite control practices and public perception of parasitic diseases: a survey of dog and cat owners. Prev Vet Med. 2015;122:174-80

54. Hill SL, Cheney JM, Taton-Allen GF, Reif JS, Bruns C, Lappin MR. Prevalence of enteric zoonotic organisms in cats. J Am Vet Med Assoc. 2000;216:687-92. 
55. Hackett T, Lappin MR. Prevalence of enteric pathogens in dogs of northcentral Colorado. J Am Anim Hosp Assoc. 2003;39:52-6.

56. Gates MC, Nolan TJ. Endoparasite prevalence and recurrence across different age groups of dogs and cats. Vet Parasitol. 2009;166(1-2):153-8.

57. Sulaiman IM, Fayer R, Bern C, Gilman RH, Trout JM, Schantz PM, et al. Triosephospate isomerase gene characterization and potential zoonotic transmission of Giardia duodenalis. Emerg Infect Dis. 2003;9:1444-52.

58. Berilli F, Di Cave D, De Liberato C, Franco A, Scaramozzino P, Orecchia P. Genotype characterization of Giardia duodenalis isolates from domestic and farm animals by SSU-rRNA gene sequencing. Vet Parasitol. 2004;122:193-9.

59. Barutzki D, Thompson RC, Wielinga C, Parka U, Schaper R. Observations on Giardia infection in dogs from veterinary clinics in Germany. Parasitol Res. 2007;101:153-6.

60. Souza SL, Gennari SM, Richtzenhain LJ, Pena HF, Funada MR, Cortez A, et al. Molecular identification of Giardia duodenalis isolates from humans, dogs, cats and cattle from the state of Sao Paulo, Brazil, by sequence analysis of fragments of glutamate dehydrogenase (gdh) coding gene. Vet Parasitol. 2007;149:258-64.

61. Scorza AV, Ballweber LR, Tangtrongsup S, Panuska C, Lappin MR. Comparisons of mammalian Giardia duodenalis assemblages based on the $\beta$-giardin, glutamate dehydrogenase and triose phosphate isomerase genes. Vet Parasitol. 2012;189:182-8.

62. Pallant $L$, Barutzki D, Schaper R, Thompson RCA. The epidemiology of infections with Giardia species and genotypes in well cared for dogs and cats in Germany. Parasit Vectors. 2015;8:2.

63. Xiao L, Fayer R. Molecular characterisation of species and genotypes of Cryptosporidium and Giardia and assessment of zoonotic transmission. Int J Parasitol. 2008;38:1239-55.

64. Minetti C, Lamden K, Durband C, Cheesbrough J, Fox A, Wastling JM. Determination of Giardia duodenalis assemblages and multi-locus genotypes in patients with sporadic giardiasis from England. Parasit Vectors. 2015;8:44.

65. Lucio-Forster A, Griffiths JK, Cama VA, Xiao L, Bowman DD. Minimal zoonotic risk of cryptosporidiosis from pet dogs and cats. Trends Parasitol. 2010;26:174-9.

66. Ryan U, Fayer R, Xiao L. Cryptosporidium species in humans and animals: current understanding and research needs. Parasitology. 2014;11:1-19.

67. Xiao L, Cama VA, Cabrera L, Ortega Y, Pearson J, Gilman RH. Possible transmission of Cryptosporidium canis among children and a dog in a household. J Clin Microbiol. 2007:45:2014-6.

68. Bowman DD, Lucio-Forster A. Cryptosporidiosis and giardiasis in dogs and cats: veterinary and public health importance. Exp Parasitol. 2010; 124:121-7.

69. Dakkak A. Guidelines for diagnosis, surveillance and control of echinococcosis. Geneva Switzerland: Veterinary Public Health, World Health Organization; 1992 Echinococcus-hydatidiosis in North Africa: geographical distribution of species and strains and prevalence in man and animals.

70. Caccio S, Ryan U. Molecular epidemiology of giardiasis. Mol Biochem Parasitol. 2008;160:75-80

71. Thompson RCA, Smith A. Zoonotic enteric protozoa. Vet Parasitol. 2011;182:70-8

72. Traversa D. Pet roundworms and hookworms: a continuing need for global worming. Parasit Vectors. 2012:5:91.

73. Fahrion AS, Schnyder M, Wichert B, Deplazes P. Toxocara eggs shed by dogs and cats and their molecular and morphometric species-specific identification: is the finding of $T$. cati eggs shed by dogs of epidemiological relevance? Vet Parasitol. 2011;177:186-9.

74. Nijsse R, Mughini-Gras L, Wagenaar JA, Ploeger HW. Coprophagy in dogs interferes in the diagnosis of parasitic infections by faecal examination. Vet Parasitol. 2014;204(3-4):304-9.

75. Parsons JC. Ascarid infections of cats and dogs. Vet Clin North Small Anim Pract. 1987;17:1307-39.

76. Fok E, Szatmari V, Busak K, Rozqonyi F. Prevalence of intestinal parasites in dogs in some urban and rural areas of Hungary. Vet Q. 2001;23:96-8.

77. Habluetzel A, Traldi G, Ruggieri S, Attili AR, Scuppa P, Marchetti R, et al. An estimation of Toxocara canis prevalence in dogs, environmental egg contamination and risk of human infection in the Marche region of Italy. Vet Parasitol. 2003;113:243-52.

78. Le Nobel WE, Robben SR, Döpfer D, Hendrikx WM, Boersema JH, Fransen F, Eysker M. Infections with endoparasites in dogs in Dutch animal shelters. Tijdschr Diergeneeskd. 2004;129:40-4.

79. Martínez-Carrasco C, Berriatua E, Garijo M, Martínez J, Alonso FD, de Ybáñez RR. Epidemiological study of non-systemic parasitism in dogs in southeast
Mediterranean Spain assessed by coprological and post-mordem examination. Zoonoses Public Health. 2007:54:195-203.

80. Haralambidis ST. Toxocarosis. In: Haralambidis ST, editor. Issues of parasitology that concern public health in Thessaloniki. Thessaloniki, Greece: University Studio Press; 1993. p. 41-5.

81. Villeneuve A, Polley L, Jenkins E, Schurer J, Gilleard J, Kutz S, et al. Parasite prevalence in fecal samples from shelter dogs and cats across the Canadian provinces. Parasit Vectors. 2015;8:281.

82. Fisher M. Toxocara cati: an underestimated zoonotic agent. Trends Parasitol, 2003;19:167-70.

83. Overgaauw PA. Aspects of Toxocara epidemiology: human toxocarosis. Crit Rev Microbiol. 1997;23:215-31.

84. Smith H, Noordin R. Diagnostic limitations and future trends in the serodiagnosis of human toxocariasis. In: Holland CV, Smith HV, editors. Toxocara: the enigmatic parasite. Wallingford: CABI Publishing; 2006. p. 89-112.

85. Xinou E, Lefkopoulos A, Gelagoti M, Drevelegas A, Diakou A, Milonas, Dimitriadis AS. CT and MR imaging findings in cerebral toxocaral disease. Am J Neuroradiol. 2003;24:714-8

86. Haralambidou S, Vlachaki E, loannidou E, Milioni V, Haralambidis S, Klonizakis I. Pulmonary and myocardial manifestations due to Toxocara canis infection. Eur J Intern Med. 2005;16:601-2.

87. Theodoridis I, Frydas S, Papazahariadou M, Hatzistilianou M, AdamamaMoraitou KK, Di Gioacchino M, Felaco M. Toxocarosis as zoonosis. A review of literature and the prevalence of Toxocara canis antibodies in 511 serum samples. Int J Immunopathol Pharmacol. 2001;14:17-23.

88. Jenkins DJ, Mckinlay A, Duolong H, Bradshaw H, Craig PS. Detection of Echinococcus granulosus coproantigens in faeces from naturally infected rural domestic dogs in south eastern Australia. Aust Vet J. 2006;84:12-6.

89. Sotiraki S, Chaligiannis I. Cystic echinococcosis in Greece. Parasite. 2010;17:205-10.

90. Katzoura V, Diakou A, Kouam MK, Feidas H, Theodoropoulou H, Theodoropoulos G. Seroprevalence and risk factors associated with zoonotic parasitic infections in small ruminants in the Greek temperate environment. Parasitol Int. 2013;62:554-60.

91. Chaligiannis I, Maillard S, Boubaker G, Spiliotis M, Saratsis A, Gottstein B, Sotiraki S. Echinococcus granulosus infection dynamics in livestock of Greece. Acta Trop. 2015;150:64-70

\section{Submit your next manuscript to BioMed Central and we will help you at every step:}

- We accept pre-submission inquiries

- Our selector tool helps you to find the most relevant journal

- We provide round the clock customer support

- Convenient online submission

- Thorough peer review

- Inclusion in PubMed and all major indexing services

- Maximum visibility for your research

Submit your manuscript at www.biomedcentral.com/submit
) Biomed Central 